\title{
The Appropriateness of Using the S-R Inventory of Anxiousness to Measure Sources of Behavioral Variability
}

\author{
Velma A. Kameoka \\ Washington State University \\ Junko Tanaka-Matsumi \\ Hofstra University
}

The S-R Inventory of Anxiousness is critically examined for its appropriateness as a research strategy to demonstrate sources of behavioral variance. The purpose, development, use of the inventory, and ensuing analysis are reviewed. Three major problems are discussed in light of the research questions. These problems include (1) the apparent lack of distinction between person and mode of response, (2) influence of the nonrandom selection of situation and mode of response on the results of the analysis, and (3) problems in specifying and assessing the nature of person-situation interactions. Although initial efforts to statistically demonstrate variance contribution of interactions deserve recognition, it is maintained that the variance components approach and previous application of the S-R Inventory of Anxiousness do not lead to clarifying the specific nature of person-situation interactions in influencing anxiousness. Rather, it is suggested that future research on person-situation interactions would benefit by identifying specific person and situation characteristics and incorporating aspects of both these factors into a systematic research design.

Whether situation variables or person variables constitute the major source of behavioral variance has been a topic of theoretical debate and empirical research (e.g., Argyle \& Little, 1972; Bowers, 1973; Ekehammar, 1974; Endler, 1975, 1977; Endler \& Magnusson, 1976, 1978;

APPLIED PSYCHOLOGICAL MEASUREMENT

Vol. 5, No. 2, Spring 1981, pp. 229-235

(C) Copyright 1981 Applied Psychological Measurement Inc. 0146-6216/81/020229-07\$1.35
Krauskopf, 1978; Mischel, 1968, 1973). The aim of early work on this issue was to demonstrate either cross-situational consistency or situational specificity of behaviors. Empirical support for the former implied that person variables provide more important data in explaining behavioral variation, and support for the latter suggested that situation rather than person variables are of greater predictive value. However, recognition that both variables are essential determinants of behaviors led to the emergence of the interactionist position, which has since gained wide support as a logical resolution of this personsituation debate. Thus, person-situation interactions became a substantive topic in its own right and, as such, has generated extensive studies employing a variety of methodological strategies.

The most popular research strategy has attempted to demonstrate the magnitude of interactive effects relative to the separate effects of persons and situations. Endler, Hunt, and Rosenstein's (1962) application of this strategy is particularly noteworthy. In this early and influential study, the authors introduced and developed the self-report S-R Inventory of Anxiousness and used it as a "variance components strategy" (Endler, 1966) to estimate and to compare the relative effects of individual differences (person), situation, and person-situation interaction sources in accounting for total 
variation in anxiety responses. The S-R Inventory was used by the authors as a method for data collection in response to the apparent need for assessment techniques that incorporated person, situation, and response mode characteristics in measuring individual differences in anxiety.

Another line of research moves away from mere statistical comparison of variance components sizes derived from single administrations of self-report measures, such as the series of studies reported by Endler and his colleagues (Endler, 1966, 1975, 1977; Endler \& Hunt, 1966, 1969; Endler, Hunt, \& Rosenstein, 1962). Instead, the research emphasizes measurement of specific behaviors, in vivo, across different situations and different individuals. That is, the research is directed toward understanding how individuals differ among themselves in their responses in specified situations and how the individual's behaviors vary as a function of change in situational variables. The associated methods of data collection-such as behavioral sampling (Mariotto \& Paul, 1975); direct observation and monitoring of behaviors (Goldfried \& Kent, 1972); daily record keeping of a particular response (Epstein, 1979); ratings by significant others (Bem \& Allen, 1974); and systematic variation of situational factors-have expanded the scope of the person-situation interaction literature and have correspondingly contributed to the study of personality. In this research context, self-report measures, such as the S-R Inventory of Anxiousness, can meaningfully function as one type of dependent measure (e.g., Paul, 1966) but not as an all inclusive "research design," as Endler and his colleagues (Endler, 1966, 1975, 1977; Endler \& Hunt, 1966, 1969; Endler et al., 1962) have so consistently endorsed.

The present paper addresses the inadequacies of the former variance components approach as initially used by Endler and his colleagues (Endler, 1966, 1975; Endler \& Hunt, 1966, 1969; Endler et al., 1962). More specifically, in light of continued application of Endler's methodology and increased attention given to the latter empirical strategy to assess the effects of person- situation interactions, the purpose of this paper is to critically examine the appropriateness of using the S-R Inventory of Anxiousness as a research strategy to investigate sources of behavioral variability.

\section{The S-R Inventory of Anxiousness: Description and Analysis}

Endler et al. (1962) developed the S-R Inventory of Anxiousness and used it as a methodological strategy to demonstrate the relative contributions of persons, situations, modes of response, and their interactions to subject variability in anxiety (Endler \& Hunt, 1966, 1969). The original inventory consisted of 11 potentially anxiety-arousing situations. According to the investigators, these situations were selected (1) on intuitive bases and (2) for their relevance to anxiety-arousing experiences of college students. Following presentation of each situation, subjects rated themselves on a 5-point rating scale on 14 anxiety response indicators, which the investigators termed modes of response. Modes of response included both physiological and overt behavioral indicators of anxiousness and were selected to represent both positive and negative "drive." Items from the MMPI and the Taylor Manifest Anxiety Scale were also included. Therefore, a total of 154 items were rated by each subject: 14 modes of response $\times 11$ situations. In short, the inventory was conceptualized as a three-dimensional data matrix representing three main sources-Modes of Response, Situations, and Persons-and the data were treated as those obtained in an experimental design.

In the initial study, Endler et al. (1962) employed a three-way fully crossed random effects model with one observation per cell and computed mean squares for each of the three main factors (Modes of Response, Situations, and Persons) and three two-way interactions (Modes of Response $\times$ Situations, Modes of Response $\times$ Persons, Situations $\times$ Persons). The analysis indicated that in one sample the mean square for Situations was 11 times greater than the mean 
squares for Persons. As a result of this analysis, the importance of Situation in the assessment of anxiety was emphasized. However, in a subsequent analysis of the data (Endler \& Hunt, 1966) which compared the relative contributions of each variance component, it was found that individual differences among Persons, Situations, and Modes of Response, per se, did not account for a larger portion of the total variance. Instead, the results demonstrated a sizable third of the total variance to be attributable to the simple interactions between the main sources. The result was substantiated by findings of a subsequent study (Endler \& Hunt, 1969). In sum, these investigators concluded that no single source can sufficiently explain behavioral variability in anxiety; rather, interactions of the major sources of variance must be examined.

\section{Problems in Employing the S-R Inventory of Anxiousness as a Methodological Strategy to Investigate Sources of Behavioral Variability}

\section{What Does Person Represent in the}

\section{Analysis of the S-R Inventory of Anxiousness?}

Endler and Hunt (1966) concluded that person (individual differences) accounts for relatively small proportions of total variation in anxiety responses. However, person conceived as an independent source of variance raises questions: That is, what does person meaningfully represent in the authors' data analytic strategy? In their design, subjects responded specifically to 11 specific situations through 14 modes of responses (Cartwright, 1975). Obviously, individual differences in anxiousness are reflected in individual variations of response patterns. The $S$ $R$ Inventory was, in fact, designed to incorporate different modes of response such that person differences in anxiety may be discerned. To the extent that these modes of response may be considered alternatively as multiple dependent measures (Ekehammar, 1974) for the measurement of anxiousness, person differences in response patterns lead to a direct assessment of individual differences in anxiousness across situations sampled. Therefore, it is quite apparent that mode of response constitutes a characteristic of the individual and that the distinction between person and modes of response in the present context lacks empirical clarity. Rather, person is more aptly defined as "response generators" (Shine \& Bower, 1971), as conceptualized in the ANOVA model for intrasubject designs (see Hersen \& Barlow, 1976). If the inventory is to be applied and interpreted as an "experimental design" in the conventional ANOVA design sense rather than as an instrument to measure the degree of a person's self-report of anxiousness, future efforts should be directed to clarifying the distinction between person and mode of response.

\section{How Does the Selected Model and the Main Factors Influence the Results of the Analysis?}

As previously noted, the original inventory sampled 11 situations and 14 modes of response. Levels of both the Situation and Mode of Response factors were not selected at random from the population of levels for each factor (Endler et al., 1962). However, both of these factors were treated by the investigators as fully crossed and random. Their design, indeed, is more appropriately a mixed model with Persons random and Situations and Modes of Response fixed. The authors argued that because the mixedmodel assumes triple interaction to be zero and because such interaction in their study of anxiousness has "psychological meaning" (Endler, 1966), they opted for the random model. Although it is important to study triple interaction, it is an empirical question to be investigated rather than a question of a statistical model. Endler stated that "the most practical solution when using the $S-R$ Inventory is to have replications with different sample groups and to use different forms of the inventory" (Endler, 1966, p. 568). Nonetheless, the generalizability of results from each analysis may be limited. 
Furthermore, the relative contribution of the main effects can be artificially inflated as a function of the range of items selected for inclusion in modes of response and situations (Cartwright, 1975). Likewise, person variables can influence the magnitude of variance attributable to situations and mode of response (Cartwright, 1975; Golding, 1975). As empirically demonstrated by Cartwright (1975), such influences will be manifested in the coefficient of variance component, which can be obtained by forming the product of $n$ and the number of levels of the variables not included in the subscript of the variance component under consideration (Gaito, 1960). This issue is particularly critical because the authors' research questions require the comparison of variance attributable to each source with the total variance. Given this design and selection procedure for the main factors, the generalizability of the findings must be questioned.

These design and analysis problems derive from the authors' confusing application of a self-report instrument that simultaneously functions as (1) a method of data collection and (2) an experimental design that permits a statistical determination of the relative contribution of main and interactive effects to variation in anxiety responses. Related concerns have been raised by Magnusson (1976), among others (Olweus, 1977; Epstein, 1977), who pointed out that it is the applications of the variance components strategy that confuses the very important distinction between "interaction" as a theoretical issue and "interaction" as a statistical term in the ANOVA design.

\section{Does the Use of the S-R Inventory of Anxiousness Contribute to the Specification of Behavior in Situations?}

Endler and his colleagues (Endler, 1966, 1975; Endler \& Hunt, 1966, 1969; Endler et al., 1962) used the S-R Inventory of Anxiousness to demonstrate the importance of assessing person, situation, and their interactions in accounting for anxiety responses; and as such, it is a significant improvement over global trait anxiety measures. Indeed, the inventory has the advantage of asking specific responses of the subjects in specific situations. However, their method of data collection and the ensuing data analysis do not lead to specification and assessment of how particular situations and person characteristics interact to influence behavior.

Given the design employed in their research, the data merely provide information regarding the relative size of the variance attributable to each source. Although the inventory examines subjects' specific modes of response to 11 situations, the variance components analysis does not provide information regarding differential responding across situations. As their design contains single observations per cell, the triple interaction is confounded with error. Furthermore, simple main effects across subjects for each level of persons cannot be examined because each subject constitutes a level of the person factor. Thus, if person-specific responses are to be obtained in specific situations, the present design and analysis are not suitable, since each main factor is collapsed against each other in order to demonstrate variance contributions of the main sources. Although the advantage of the inventory over previous anxiety scales lies in its ability to elicit a person's specific responses in specific situations, the investigators' use of the scale needs reconsideration.

\section{Summary and Conclusion}

The series of studies conducted by Endler and his colleagues using the S-R Inventory of Anxiousness clearly indicate the importance of assessing effects due to both the person and the situation. As Cronbach (1975) has maintained, the study of human behavior must be a study of higher order interactions. Although initial efforts to demonstrate statistically the variance contribution of person-situation interactions deserve recognition, neither the variance components approach nor previous applications of the S-R Inventory of Anxiousness lead to the 
clarification of how person and situation interact to evoke specific behaviors (Magnusson, 1976; Olweus, 1977). Experimental designs are needed that permit people to respond to the presentation of situational stimuli so that their behaviors can be directly measured. In such experimental contexts, the S-R Inventory of Anxiousness can serve more productively as selfreport dependent measures across different situations. For example, Mariotto and Paul (1975) have provided direct behavioral data demonstrating the interaction effects of person and situation in their program evaluation of experimental treatments for chronic mental patients. To fully evaluate the nature of person-situation interactions, there is a definite need to specify what aspects of person and situation are being studied vis-à-vis specific target behaviors.

Recently, several papers have examined the nature of person-situation interaction from the viewpoint of improving reliability/stability coefficients of subjects' responses on self-report measures. In their attempt to clarify person variables, Bem and Allen (1974) asked subjects to report the degree to which they considered themselves "consistent" across various situations in their "friendliness." Those subjects who described themselves as "variable" across situations tended to show lower reliability coefficients when their self-ratings were correlated. Further, the same results were obtained for ratings by others and direct behavioral measures in actual situations. These results point toward specification of person and individual differences in response variability. Similar data led Epstein (1979) to conclude that "there are marked individual differences in the degree to which individuals exhibit stability in their personality profiles" (p. 1110).

Another promising line of research concerns the extent to which individuals' behaviors approach the significant level of stability. It is already clear that behavior at any particular instance is highly situation-specific (Mischel, 1968). However, situational specificity of behavior does not necessarily imply that behavior- al stability and consistency is lacking. For example, Epstein (1979) asked subjects to keep daily records of pleasant and unpleasant emotional experiences and response tendencies for those experiences. He then computed betweensubject reliability coefficients for pleasant and unpleasant experience variables and found that mean reliability coefficients increased as a function of the number of days sampled. As Epstein reported, "when measures of behavior are averaged over an increasing number of events, stability coefficients increase to high levels" ( $p$. 1097). Therefore, when subjects rated their specific emotional experiences in specific daily situations, reliability of the method itself improved to a high degree. Additionally, when behavioral measures were sampled and averaged across occasions, validity coefficients reached higher levels of statistical significance. Similar patterns demonstrating significant relationships between person characteristics (i.e., attitudes) and multiple behavioral criteria were shown by Ajzen and Fishbein (1977) when greater degrees of correspondence existed between predictor and criterion measures.

The above findings strongly indicate that effective self-report measures should specify situations and responses; furthermore, these measures should be administered in relevant situations alone. To the contrary, Endler and his colleagues asked subjects to respond to all the 11 different situations in one self-report testing session. Such strategies do not yield data on situation-specific responses; thus, variance due to situation, person, and their interaction does not aid clarification of these three factors. In short, the more specific the form of an inventory becomes, the more reliable are the resulting data. Single occasion scores on standard personality measures characterized by nonspecific and global indices of personality without situational restrictions fail to achieve acceptable levels of reliability across situations and fail to predict a specific person's response in specific situations. However, as recent evidence suggests, when single occasion measurements of both predictor 
and criterion variables are "aggregated" across occasions, behavioral predictions markedly improve (Epstein, 1980). In sum, future research on person-situation interactions would benefit by identifying specific person and situation characteristics and incorporating aspects of these factors in a systematic research design.

\section{References}

Ajzen, 1., \& Fishbein, M. Attitude-behavior relations: A theoretical analysis and review of empirical research. Psychological Bulletin, 1977, 84, 888-918.

Argyle, M.. \& Little, B. R. Do personality traits apply to social behavior? Journal for the Theory of Social Behavior, 1972, 2, 1-35.

Bem, D. J., \& Allen, A. On predicting some of the people some of the time: The search for crosssituational consistencies in behavior. Psychological Review, 1974, 81, 506-620.

Bowers, K. S. Situationism in psychology: An analysis and a critique. Psychological Review, 1973, 80. 307-336.

Cartwright, D. S. Trait and other sources of variance in the S-R Inventory of Anxiousness. Journal of Personality and Social Psychology, 1975, 32. 408-414.

Cronbach, L. J. Beyond the two disciplines of scientific psychology. American Psychologist, 1975, 30. 116-127.

Ekehammer, B. Interactionism in personality from a historical perspective. Psychological Bulletin, 1974, 81, 1026-1048.

Endler, N. S. Estimating variance components from mean squares for random and mixed effects analysis of variance models. Perceptual and Motor Skills, 1966, 22, 559-570.

Endler, N. S. The case for person-situation interactions. Canadian Psychological Review, 1975, 16, 12-21.

Endler, N. S. The role of person-by-situation interactions in personality theory. In I. C. Uzgris \& F. Weizmann (Eds.), The structuring of experience. New York: Plenum Press, 1977.

Endler, N. S., \& Hunt, J. McV. Sources of behavioral variance as measured by the S-R Inventory of Anxiousness. Psychological Bulletin, 1966, 65, 336-346.

Endler, N. S., \& Hunt, J. McV. Generalizability of contributions from sources of variance in the S-R Inventories of Anxiousness. Journal of Personality, 1969, 37, 1-24.
Endler, N. S. Hunt, J. McV., \& Rosenstein, A. J. An S-R Inventory of Anxiousness. Psychological Monographs, 1962, 76, (17, Whole No. 536).

Endler, N. S., \& Magnusson, D. (Eds.). Interactional psychology and personality. Washington, DC: Hemisphere, 1976.

Endler, N. S., \& Magnusson, D. But interactionists do believe in people! Response to Krauskopf. Psychological Bulletin, 1978, 85, 590-592.

Epstein, S. Traits are alive and well. In D. Magnusson \& N. S. Endler (Eds.), Personality at the crossroads: Current issues in interactional psychology. New York: Halsted Press, 1977.

Epstein, S. The stability of behavior: I. On predicting most of the people much of the time. Journal of Personality and Social Psychology, 1979, 37, 1097-1126.

Epstein, S. The stability of behavior: II. Implications for psychological research. American Psychologist, 1980, 35, 790-806.

Gaito, J. Expected mean squares in analysis of variance techniques. Psychological Reports, 1960, 7, 3-10.

Goldfried, M. R., \& Kent, R. N. Traditional versus behavioral personality assessment: A comparison of methodological and theoretical assumptions. Psychological Bulletin. 1972, 77, 409-420.

Golding, S. L. Flies in the ointment: Methodological problems in the analysis of the percentage of variance due to persons and situations. Psychological Bulletin, 1975, 82, 278-288.

Hersen, M., \& Barlow, D. H. Single case experimental designs: Strategies for studying behavior change. New York: Pergamon Press, 1976.

Krauskopf, C. J. Comments on Endler and Magnusson's attempt to redefine personality. Psychological Bulletin, 1978, 85, 280-283.

Magnusson, D. The person and the situation in an interactional model of behavior. Scandinavian Journal of Psychology, 1976, 17, 253-271.

Mariotto, M. J., \& Paul, G. Persons versus situations in the real-life functioning of chronically institutionalized mental patients. Journal of Abnormal Psychology, 1975, 84, 483-493.

Mischel, W. Personality and assessment. New York: Wiley, 1968.

Mischel, W. Toward a cognitive social learning reconceptualization of personality. Psychological Review, 1973, 80, 252-283.

Olweus, D. A critical analysis of the "modern" interactional position. In D. Magnusson \& $\mathbf{N}$. S. Endler (Eds.), Personality at the crossroads: Current issues in interactional psychology. New York: Halsted Press, 1977. 
Paul, G. L. Insight versus desensitization in psychotherapy. Stanford, CA: Stanford University Press, 1966.

Shine, L. C., \& Bower, S. M. A one-way analysis of variance for single-subject designs. Educational and Psychological Measurement, 1971, 31, 105-113.

\begin{abstract}
Author's Address
Send requests for reprints or further information to Velma A. Kameoka, The Program in Measurement, Indiana University, 744 Ballantine Hall, Bloomington IN 47405.
\end{abstract}

